\title{
Translation as 'Rewriting': Revisiting Translation Views of Tagore and Lefevere
}

SUVASH CHANDRA DASGUPTA

\begin{abstract}
Translation involves the task of transferring a text from the source language to the target one. During the process of this transfer, the source text is rewritten and eventually gets accepted in the receptor language as the 'rewriting of the original'. Tagore for the first time applied the word 'rewriting' as an equivalent of creative translation but left it unexplained. Translation practices of Tagore and a few other translators confirm his belief that translation creates a new independent work. Lefevere gives the word a new lease of life in the 1980s through his writings and it has since come to be associated with his name. Both Tagore and Lefevere made theoretical contribution to the concept of 'rewriting'. One needs to revisit their translation views to understand how 'rewriting' of the original comes about in the receptor language.
\end{abstract}

Keywords: Transfer, Source Language, Target Language, Source Text, Receptor Language, Equivalent, Rewriting.

\section{Introduction}

J. C. Catford defines translation as "the replacement of textual material in one language (SL) by equivalent textual material in another language (TL) (Catford 1965: 20)". Accordingly, translation, whatever be its aim and purpose, involves the task of transferring a particular text from one language to another. What actually transpires during the process of this linguistic transfer is that the source text is rewritten in the target language and that the newly-written text is eventually received in the receptor language as the 'rewriting' of the original text. 
In his attempt to trace the genealogy of the term 'rewriting', André Lefevere takes us back on a historical journey down to the remote past before touching upon its application and significance in translation literature. According to him, St. Augustine is the first to have made one of the finest statements of the "doctrine" of 'rewriting' in the Western literature (Lefevere 1992: 5). He used the word 'rewriting' regarding the interpretation of the Bible when he came to know that the behaviour of the Church members did not conform to the lesson of a few pages of the Scripture. Hence, he instructed his devoted followers to manipulate the contents of those pages and 'rewrite' them in such a way that they corresponded to the 'teachings' of the Bible. By the word 'rewrite' Augustine seems to have implied re-interpretation of those pages of the Bible rather than their re-translation. But the word 'rewriting', as used by Augustine, does not seem to signify what is popularly known as 'translation' today. Moreover, the word 'rewriting' did not gain currency in the Western world and more particularly in the translation literature until Lefevere's Translation, Rewriting, and the Manipulation of the Literary Fame (1992) gave it a new lease of life. Interestingly, long before the appearance of Lefevere's book, Rabindranath Tagore used the word 'rewriting' to imply 'creative translation' in 1915 in connection with the translation of his short stories. Surprisingly, neither the word nor the concept found its 'habitation and name' in translation literature and with the passage of time somehow it got slipped into oblivion. Consequently, he did not get the due critical recognition from translation scholars and critics for inventing such a word. Shyamal Kumar Sarkar (1977: 66-85) made the maiden attempt on bringing together many of Tagore's statements and remarks about translation in his essay "Tagore on Translation". But he throws no light on the word or the concept 'rewriting' in his essay. In Translation as Discovery and Other Essays on 
Indian Literature in English Translation, Sujit Mukherjee (1994: 101-124) made the first-ever critical study of Tagore's own translations but the theoretical aspects of his translation thinking found no place in his discussion. In an exhaustive introduction to the English Writings of Rabindranath Tagore, Sisir Kumar Das (1994: 9-34) made a detailed discussion on Tagore's own translation of poems but he made no mention of his translation thoughts. In Kabir Anubad (1998) Ashru Kumar Sikdarmade no reference to the word 'rewriting' because his main concern in the book was the poet's own translation of his poems. In Englander Dikprante Rabir Uday Rabir Asta, Chanchal Kumar Brahma (2000: 17-23) made a brief discussion about Tagore's translation thoughts but he did not take up for discussion Tagore's concept 'rewriting'. Hence there is a research gap involving Tagore's concept of 'rewriting' and nobody has yet taken it up for an in-depth study from the point of view of translation poetics. What made matters worse for Tagore is that unlike Lefevere he did not write any essay or book, nor did he deliver any lecture on translation/'rewriting' as Arnold did in his famous lecture "On Translating Homer" (1861). The objective of this paper will be, in the first place, to interpret 'rewriting' in the light of the translation practices of Tagore and others. Secondly, Lefevere's concept of 'rewriting' will be discussed with special reference to his shift from the term "refraction" to "rewriting". Thirdly, an attempt will be made here to revisit the views of Tagore and Lefevere on 'rewriting' and to examine the application of the word or concept 'rewriting' in translation literature.

\section{Tagore and 'Rewriting'}

Rabindranath Tagore (1861-1941) seems to be the first to have conceived translation as 'rewriting' or re-creation of the original or source text. He seems to have formed this 
theoretical concept about translation from his first-hand translating experience (Dasgupta 2012: 134) While talking about the translation of his short stories, as proposed by Macmillans, he uses the word 'rewriting' for the first time in his letter to Rothenstein (dated 31 Dec. 1915). By 'rewriting' he implies creative translation as distinguished from literal rendering or what he calls 'translating'. Here is the relevant section of Tagore's letter which contains the word 'rewriting':

Macmillans are urging me to send them some translations of my short stories but I am hesitating for the reason that the beauty of the originals can hardly be preserved in translation. They require rewriting in English, not translating. That can only be done by the author himself, but I do not have sufficient command of English to venture to do it (emphasis added) (Lago 1972: 216).

This chance remark made by Tagore exclusively for selftranslation underscores an important concept of translation, namely 'rewriting'. He did not explain the term except making a distinction between 'rewriting' and 'translating', the former being concerned with 'creative' translation and the latter with 'translating' or literal rendering. He does not seem to have made this distinction as part of theorizing about translation in general but as part of an internal urge for self-translation. One possible misconception about 'rewriting' needs to be dispelled here. Though with regard to his self-translation Tagore seems to have considered 'rewriting' and creative translation as identical, there is a basic difference between them. What he says about 'rewriting' in his letter to Rothenstein does not apply to translation in general. Even many of his post-Gitanjali rewritings do not rise to the level of creative translation. Normally 'rewriting' cannot be labeled as creative translation unless it is tinged with the imaginative power of the rewriter. 
Tagore seems to have dismissed 'translating' or literal translation here in favour of 'rewriting', for his genius was unsuitable for 'the humble and laborious task of translation, which involves an act of self-denial' (Bose 541). The creative self in him, Bose seems to imply, always clamoured for expression while the translating self demanded total selfeffacement for rendering a pre-existing text. This explains why he writes to Ajit Chakravorty from Urbana on 13 March 1913, "In fact, one cannot quite translate one's own works" (Sarkar 2013: 164). Again to Ramananda Chatterji he wrote on 28 October 1917, "This is my difficulty that I cannot translate, I have to write almost anew" (Sarkar 2013: 166). It was the inherent creative urge in him that set Tagore writing anew or 'rewriting' the original during the period of his convalescence in March/April 1912 in the idyllic natural ambience East Bengal. It was from his first-hand experience of selftranslating that Tagore developed the concept of 'rewriting' which later came to be accepted as a seminal concept in the history of modern translation. No one before him had applied the word 'rewriting' as an equivalent of translation. It may be mentioned in this context that Roman Jacobson (1959: 114) spoke of three kinds of translation - intralingual, interlingual and intersemiotic in his classic essay "On Linguistic Aspects of Translation, 'interlingual translation' being one of the three implying translation from one language to another. But he could not anticipate the emergence of 'rewriting', as initiated by Tagore, in the history of translation. According to Tagore, the objective of 'rewriting' is to take the soul of the original and to 'reincarnate' it in the target language. This transmigration of the soul of the original is, in his view, 'an act of creation'. This transmigration comes about only when a creative writer is engaged in this task. Tagore's oft-quoted letter to Indira Devi (dated 6 May 1913) seems to give us an insight into 'rewriting', as understood by Tagore: 
... I took up the poems of Gitanjali and set myself to translate them one by one ... I simply felt an urge to recapture, through the medium of another language, the feelings and sentiments which had created such a feast of joy within me in past days. The pages of a small exercise-book came gradually to be filled, and with it in my pocket I boarded the ship (emphasis added) (Chakravarty 2003: 20-21).

Tagore here talks of 'recapturing' in his rendering the creative mood or 'ecstasy', he has experienced while writing the original Gitanjali (1910) poems and he tries to successfully 're-enact' and 're-live' the original 'creative process' in order to 'rewrite' the poems in English. Though he does not explicitly mention the word 'rewriting' here, what he says in the italicized line seems to suggest what he means by 'rewriting'.

Again, Tagore's views on 'rewriting' find expression in his letter to Kanti Chandra Ghosh praising his excellent translation of Rubaiyat of Omar Khayyam in Bengali. Both the Bengali and its translated versions are reproduced below for the convenience of the bilingual readers:

বাংলা ছন্দে তুমি ওমর খৈয়ামের যে তর্গ্গমা করেছো তা গ্রন্থ আকারে প্রকাশের পূর্বের আমি দেথেচি । এ রকম কবিতা এক ভাযার থেকে অন্য ভাষার ছাঁচে ঢেলে দেওয়া কঠিন। কারণ এর প্রধান জিনিসটা বস্তু নয়, গতি । ফ্রিটজ জেরাল্ড ও তাই ঠিকমতো তর্জ্সা করেননি - মূলের ভাবটা দিয়ে সেটাকে নূতন করে সৃষ্টি করা দরকার ।

I have seen your translation of Omar Khayyam in Bengali rhymed verse much before its publication in a book form. It is difficult to cast the poetry of one language in the mould of 
another, for its main focus is on dynamism rather than matter. Even Fitzgerald could not translate Khyyam accurately-one needs to re-create the whole thing with the feeling of the original (emphasis added) (my translation) (Ghosh 1921: 2).

Tagore concludes his letter emphasizing the 're-creation' of the text with the emotive feeling of the original. In other words, all he wants is the re-creation or 'rebirth' of the original rather than its lifeless rendering in the receptor language. Ghosh did the creative act of 'rewriting' or 're-creating' Omar Khayyam in Bengali based on his intuitive 'feeling' or imaginative assimilation of the original Persian poems. His Rubaiyat of Omar Khayyam in Bengali do not suffer from the strain of translation and stand as independent new poems. Even though Fitzgerald 'manipulated' Khayyam in such a way in his rendering that the culture and poetics of the time are integrally wedded in his English version. Thus, he succeeded in recreating Khayyam in English as if he were a Victorian poet. Sadly, Tagore could not appreciate the translated Khayyam in English.

\section{Lefevere and 'Rewriting'}

Andre' Lefevere is one of the leading Translation Studies scholars of the Anglo-Saxon worlds. He came to be widely known as an authority on translation with the publication of Translation, Rewriting, and the Manipulation of Literary Fame (1992). He considers translation, criticism, editing, and historiography as forms of "refraction" or "rewriting". $\mathrm{He}$ propounds the theory of 'rewriting' at a time when Translation Studies was all set to take a 'Cultural Turn' towards the end of the 1980s. The publication of Translation, History, and Culture (1990) co-edited by Lefevere and Bassnett is a momentous event in the history of Translation Studies. This anthology contains a remarkable article by Mary Snell-Hornby titled "Linguistic Transcoding or Cultural Transfer? A Critique 
of Translation Theory in Germany" in which she proposes a shift from "text" as a translation unit to culture. It was in the introduction to Translation, History, and Culture (1990) that Lefevere and Bassnett announced the "cultural turn" (Lefevere and Bassnett 1990: 12). This anthology has been recognized by posterity as marking the beginning of the Cultural Turn in Translation Studies (Gentzler 1993: 188). It is against this changing scenario that Lefevere develops the idea of translation as a form of 'rewriting' by which he means that any text produced on the basis of another has the intention of adapting that other text to a certain ideology or to a certain poetics, within the cultural system of the target language. In his article "Why Waste Our Time on Rewrites" (1985), he famously declares: "Translation is probably the most obvious instance of rewriting (Hermans 1985: 234). But for him, 'rewriting' was never an 'innocent' aesthetic thing, as it was with Tagore. According to Lefevere, translation always requires 'a context' in which it takes place, a 'history from which a text emerges and into which a text is transposed (Bassnett and Lefevere 1990: 11)". Translation or 'rewriting', therefore, involves something more than the mere engagement of a translator with an original text or the linguistic transmission of the source text to the target one.

Lefevere's theory of 'rewriting' is believed to have been developed from his concept of 'refraction'. It would be profitable at this stage to have some idea about it in order to understand his concept of 'rewriting'. In his article "Translated Literature: Towards an Integrated Theory" (1981) he introduces the concept of the 'refracted text' by which he means 'texts that have been processed for a certain audience (children, for example) or adapted to a certain poetics or certain ideology' (Gentzler 1993: 140). Abridged or edited versions of classics for children or for general television viewers might be described as the most obvious forms of 
refractions. In Germany many texts by diverse writers such as Heine and Schller were very often refracted to conform to a specific poetics and ideology. In another article called "Mother Courage's Cucumbers: Text, System and Refraction in a Theory of Literature" (1982) he defines the term 'refraction' as "the adaptation of a work of literature to a different audience, with the intention of influencing the way in which that audience reads the work (Venuti 2000: 235). He also shows how Brecht's work has been refracted in the West to suitably conform to the prevailing artistic norms and political ideology of the time. It is from the concept of 'refraction' that he moves on to that of 'rewriting'. In 1985 he adopts the concept of 'rewriting' as an equivalent of the term 'refraction' so as to mean any text produced on the basis of another with the intention of adapting that other text to a certain ideology or to a certain poetics and / or to both (Hermans 127).

The theory of 'rewriting', as enunciated in the general editors' preface to Translation, Rewriting and the Manipulation of Literary Fame, has been famously described as the "rewriting of an original text" (Lefevere 1992: vii). According to the editors, all kinds of 'rewritings', irrespective of their 'intention' and purpose, are governed by some kinds of 'ideology' and 'poetics' and they manipulate literature to function in a particular way. Rewriting is always resorted to in the service of those in power and authority. It can acquaint the writers of a particular country or society with new concepts, new genres and new literary devices prevailing in foreign literatures so that they can enrich their own literature assimilating them.

\section{Tagore and Lefevere Contrasted}

Tagore and Lefevere stand poles apart from one another in their views about 'rewriting'. Tagore follows the Romantic notions of "authorial originality" which makes him 'recapture' 
or 're-create' the source text, be it his own Bengali writings or those by others. Lefevere, on the other hand, dismisses the Romantic view of "authorial originality" and addresses translated text with the same seriousness a traditionally original work is treated. With Tagore 'rewriting' is basically a creative endeavour and there is no manipulative intention about it. On the contrary, Lefevere considers the original or the source text amenable to manipulation according to the choice or intention of the translator. According to him, the translator has the liberty to 'manipulate' rewriting to serve the purpose of those in authority. In Translation, Rewriting, and the Manipulation of Literary Fame (1992) Lefevere shows how power, poetics and ideology impact translation to function in a subtle way making it a 'rewriting' of the original text. But Tagore does not have any such engagement with the forces of power, poetics, and ideology. That is why he rewrites the Gitanjali poems creatively, drawing on the feelings and sentiments of the original. Thus, the poems undergo a creative 're-incarnation' in the English language and seem to have come spontaneously from the poet's heart (Dasgupta 2012: 138-139).

\section{Conclusion}

From the foregoing discussion it is now quite evident that the names of both Tagore and Lefevere are closely associated with the genealogy of 'rewriting' and its application in the history of translation. Unlike Lefevere Tagore does not get the critical attention that he so justly deserves for using the word 'rewriting' for the first time in translation literature. Lefevere's Translation, Rewriting, and the Manipulation of Literary Fame (1992) has already become a famous book in the history of Translation. Though Tagore articulated most of his translation views even before the publication of Walter Benjamin's classic essay The Task of the Translator (1923), he remains a much- 
neglected figure in this new discipline. His translation views remain unrecognized even today in the mainstream translation thinking as does his concept of 'rewriting'.

\section{References}

BASSNeTt, SUSAN and ANDRE LeFEVERE. (eds.). 1990. Translation, History and Culture. London and New York: Pinter Publishers.

Bose, Buddhadeva. 2010. Buddhadeva Basur Prabandha

Samagra. Kolkata: Paschimbanga Bangla Academy.

Chakravarty, Amiye Kumar. (ed.). 1961, 2003. A Tagore Reader. Calcutta and Delhi: Rupa \& Co.

CATford, J. C. 1965. A Linguistic Theory of Translation: An

Essay in Applied Linguistics. London: Oxford University Press.

DAsGuPTA, S. 2012. Tagore's Concept of Translation: A Critical Study. Indian Literature. Vol. LVI No. 3 (MayJune 2012: 269).132-144.

GENTZLER, EDWIN. 1993. Contemporary Translation Theories. London and New York: Routledge.

GHOSH, KANTI ChANDRA. 1983. Rubaiyat of Omar Khayyam. Calcutta: Katha O Kahini (Rpt).

HERMANS THEO. (ed.). 1985. The Manipulation of Literature:

Studies in Literary Translation. London: Croom Helm.

KHAYYAM, OMAR. 1868. Rubaiyat of Omar Khayyam (Edward

Fitzgerald, Trans.). London: Bernard Quaritch.

LAGO, MARY M. 1972. Imperfect Encounter: Letters of William Rothenstein and Rabindranat Tagore 1911-1941.

New York: Harvard University Press.

LEFEVERE, ANDRE. 1992. Translation, Rewriting, and the Manipulation of Literary Fame, London and New York: Routledge.

Roy, Mohit Kumar. (ed.). 2008. The English Writings of Rabindranath Tagore. Delhi: Atlantic Publishers. 
SARKAR, ShyAmal Kumar. 2013. Collected Papers on Rabindranath Tagore. Kolkata: Deys.

Venuti, Lawrence. (ed.). 2000. The Translations Studies Reader. London and New York: Routledge.

***

Cite this work:

DAsGuPTA, SUVASH CHANDRA. 2020. Translation as 'Rewriting': Revisiting Translation Views of Tagore and Lefevere. Translation Today, Vol. 14(1). 56-76. DOI: 10.46623/tt/2020.14.1.ar5 